\title{
SECTOR TEXTIL COLOMBIANO Y SU INFLUENCIA EN EL DESARROLLO DE ECONOMÍA DEL PAÍS
}

Gloria Tatiana Cuartas Galvis

Facultad de Negocios, Gestión y Sostenibilidad

Especialización en Gestión Empresarial

tatacuartasgalvis@gmail.com

\section{Resumen}

El objetivo de esta investigación es analizar el macroentorno y microentorno del sector textil colombiano, identificando los elementos que facilitan y contribuyen al desarrollo de este, así como, su relación con la sostenibilidad, a través de un análisis estratégico de las cinco fuerzas de Porter y en análisis Pestel. Se han caracterizado 15 factores críticos de éxito en cada una de las dos herramientas identificándolos según su influencia económica, tecnológica, social, política y legal, dando como resultado la existencia de un nuevo paradigma de posibilidades en el sector textil, circunstancias que contribuyen a mejorar el desarrollo del sector de una manera más ética y sostenible.

Palabras clave: macroentorno, microentorno, sector, desarrollo sostenible 
Introducción

El sector textil colombiano ha tenido un papel preponderante en el desarrollo de la economía industrial manufacturera, a través de un repaso por la historia se podrá identificar las características del mismo y como ha afrontado su reconversión productiva a lo largo de más de 10 décadas.

Para el desarrollo de la investigación se emplearon varias metodologías de gestión de

análisis Pastel y Porter, con el propósito de implementar un escenario favorable estratégico basado en el análisis de las oportunidades y amenazas, que conduzca a la asignación de recursos que permita la consolidación en nuevos nichos de mercado.

La investigación resalta que los factores críticos que crean un escenario desfavorable en el sector son: La tecnología y su bajo o nulo desarrollo, los cambios de paradigmas de consumos y una implementación ecológica como eje central del desarrollo textil, dando evidencia de la necesidad imperiosa de una reconversión del sector textil colombiano.

Se aborda que esta transformación del sector es posible es a través de la "sostenibilidad" que como estrategia competitiva y la implementación adecuada permita el desarrollo de estrategias que fortalezcan nuestra presencia internacional agregando valor.

\section{Marco Teórico}

De acuerdo a la incidencia del sector textil en la economía nacional y a los diversos retos a los cuales se ha enfrentado, es necesario explorar las diferentes referencias encontradas 
sobre los factores que han incidido en su competitividad a través de la historia; su estado actual y los factores que impactaran el desarrollo futuro del sector.

\section{Historia del sector textil en Colombia}

El sector Textil tiene un papel preponderante en la historia de la economía colombiana, a finales del siglo XVIII Gomez (2005), se remontan sus inicios donde predominaba la producción manual en talleres artesanales, los materiales más comunes eran el algodón, la lana, el fique, la iraca y el cuero, quienes a través del uso de herramientas rudimentarias como martillos, mazos, cuchillos y tijeras o mediante telares de madera, hiladoras y ruecas daban la confección textil de la época. La revolución industrial a finales del siglo XIX y la implementación del acero en la incipiente industria colombiana; favorece el primer intento de construir industria en el país; la labor artesanal permitió la exportación a Inglaterra Cuba, estados unidos de sombreros "Panamá" quien el presidente de los estados unidos Roosevelt por esa época popularizo; los cuales eran elaborados y confeccionados en Santander y Antioquia conocidos como sobreros jipijapa. Martinez (1993).

El camino de la estructuración del sector está marcado por la conformación de la fábrica textil Coltejer en 1907, donde inicia la expansión textil como consecuencia de la estabilidad institucional del país al superar la guerra de los mil días y de la apertura económica dada por el creciente y fortalecido sector cafetero como lo plantea SAAVEDRA (2003).

La tercera y Cuarta década del siglo XX, tuvo como impacto la entrada de capitales al país lo que permitió que la industria textil con un alto sentido de políticas proteccionistas e incipiente comercio internacional, se hizo uno de los sectores pioneros en la reconversión 
productiva, para esta época empresas como Coltejer, Tejicondor y Fabricato, realizaban la importación de tecnología y maquinaria para la productividad, teniendo menores costos en el mercado, permitiendo ser líderes en hilaturas y tejidos. Vega (1990).

Posterior a la segunda guerra mundial y el cierre del abastecimiento externo, se incrementó la demanda de producción textil nacional y las empresas líderes tuvieron una participación del 50\%, adicional estas empresas realizaron producción para los ejércitos combatientes como EEUU, en especial COLTEJER, a quien, en retribución, recibió maquinaria y tecnología moderna, lo que permitió que la industria nacional incursionara en el sector de la confección.

Hacia los años 50 la modernización que inundaba el mundo con teorías teylorianas de industrialización, se aplicaron a las plantas de producción nacional dando como resultados el aumento de eficiencias en mano de obra y en consecuencia incremento de productividad. Mayor Mora (1983), plantea que estos modelos generaron un alto nivel de desempleo, los obreros fueron remplazados por maquinaria y personal más capacitado.

En la década de los 70, la automatización fue la característica principal de las empresas líderes del Sector; Coltejer y Fabricato, modernizaron sus plantas implementando la automatización y la computación, lo que permitió a las exportaciones seguir con un ritmo creciente, siendo competitivos en el mercado internacional. Hacia los años ochenta, la economía mundial sufrió un proceso de recesión y la industria textil se vio afectada por la baja inversión y actualización. A razón de esto, se vio obligada a reducir costos y mejorar sus procesos, tanto productivos como administrativos. Gomez (2005).

En los años 90 las políticas económicas colombianas cambian drásticamente del sentido predominante proteccionista a un mercado de competencia internacional. Esta apertura 
coloca en riesgo el crecimiento económico y el sector que participaba en décadas anteriores con el 14,9\% del promedio del valor agregado nacional para mediados de los noventa, paso a tener solo un 7,2\%; Según GARAY S (1998), esta desaceleración está marcada por la competencia internacional y las nuevas opciones en el mercado para los Clientes; sumado al contrabando y a la revaluación del peso. Contrario a esto en esta década inicia la consolidación del sector de la confección y el posicionamiento de Colombia en los mercados internacionales; pero con insumos en su mayoría importados. Llegando al nuevo milenio la industria creció entre el 2002 y el 2007 un 47\%; jalonado básicamente por el subsector de confecciones.

En 2008 confluyeron la crisis financiera mundial, el cierre de los mercados con los aliados comerciales más importantes para Colombia como lo eran Ecuador y Venezuela y la apertura de los mercados chinos realizada por Estados Unidos y la unión Europea, ahondo la crisis y en consecuencia como lo plantea Brugen y Generalitat, 2011: Las empresas solo cumplieron con $70 \%$ de sus objetivos de ventas, resultado del aumento del contrabando abierto y técnico; la obsolescencia de maquinaria y líneas de producción y el exceso de personal.

Del 2012 al 2018 el sector afronta altibajos marcados principalmente por la sobreoferta de productos textiles en el país su mayoría con ingreso de China; baja accesibilidad de materias primas y la insuficiente producción nacional de insumos, La falta de modernización, el contrabando, la subfacturación y la revaluación de la moneda siguen siendo factores de impacto en el desarrollo de la industria textil del país. 
De este modo, se observa que desde finales del siglo XVIII donde se inicia el desarrollo de una producción textil artesanal, este tipo de manufactura ha teniendo un papel de impacto en la economía colombiana, y pese a todo el recorrido de la historia los factores económicos que afronta se mantienen en el tiempo y no han sido afrontados de manera novedosa, La apertura de mercados; el desarrollo de sistemas internos y externos de comunicación y transporte, la modernización, La calidad y bajos costos de productos importados, los cambios de paradigmas de los consumidores; todos estos han incidido a lo largo del desarrollo de la historia del sector, igual los afronta hoy en día, y aunque el sector aun subsista y sea representativo para la balanza comercial del país, es claro es que se deben generar oportunidades para el desarrollo competitivo del sector y la industria de la confección en Colombia.

\section{Panorama del sector textil en Colombia}

El crecimiento económico del país tiene un efecto directo sobre el ingreso percapita de la población afectando la demanda, para el 2019 se registró en primer trimestre del año crecimiento económico del 2,8\%, indicador que va en aumento desde el 2018 y se espera que este sea sostenible; según el FMI se prevé un continuo crecimiento que al 2020 sea del 3,6\% impulsado por las inversiones y las exportaciones. Aunque este panorama es favorable no podemos ignorar la devaluación del peso sobre el dólar según el escalafón de Bloomberg con las monedas más devaluadas en lo que va del 2019 el peso y ocupa el puesto 7, con una TRM inferior \$3.350, y un porcentaje de devaluación año corrido del 1,52\%. Indicadores que impactan directamente el sector textil en Colombia. 
El sector textil es considerándolo como una de las principales fuentes generadoras de empleo que aporta más del 21,4\% del empleo manufacturero con 542.321 empleos (Catelli, 2016). La participación en el PIB del sector textil-confecciones ha repuntado y para el año 2018 representó el 8,8\%. Según el último informe de Indexmoda (2019), se espera que el sector tenga un crecimiento constante del 4,8\% hasta el 2022. Este indicador se ve reflejado en el indicador reportado por la encuesta mensual manufacturera del DANE el gasto de los hogares tuvo un crecimiento del 3.3\%, mientras en el 2017 creció a un ritmo del 0,3\%. Ubicando el vestuario y el calzado como el segundo sector con mayor crecimiento en el 2018 del $4.71 \%$.

Para el 2018 el crecimiento de las exportaciones de prendas de vestir y productos textiles y materias primas fue del $7,1 \%$ y $6,1 \%$ respectivamente. Lo que implica un crecimiento frente a las variaciones negativas del año 2017. La importación de insumos Productos textiles y materias primas tuvo un crecimiento del $24,7 \%$ para el 2018. Las importaciones de Confección y prendas de vestir creció un 14,5\%, indicador preocupante por los mínimos precios de estos productos en el mercado nacional. DANE (2018).

Cifras del Dane, según capítulo de arancel, elaboración sectorial, reportan que Cerca del $60 \%$ de materias primas del sector textil son importadas, lo cual encarece costos frente a países con materia prima local; La participación de países en las importaciones en materia prima son China con una participación 44.3\%; India 12,4\% y Estados unidos 9,9\%.

Mientras la producción nacional de hilaturas; Tejeduría y acabado textil crece al 2,6\%. Las importaciones de estas materias primas crecen en $24,7 \%$. Fuentes oficiales de la CCCyA han informado que en el país no se producen de manera masiva los hilos e hilazas para la confección, por lo cual las empresas se ven obligadas a importar este bien que de 
momento cuenta con un arancel de entrada del 10\%. Esta situación, según explican los confeccionistas nacionales, pone los textiles colombianos inmediatamente en desventaja frente a los productos regionales, pues, aunque todos los demás materiales sean locales, la prenda ya tiene un sobre costo impositivo. La industria local no ha modernizado lo suficiente sus equipos y procesos productivos. De hecho, un estudio reveló que la inversión en el sector, como proporción del valor agregado, representa 7,7\%, mientras que el promedio manufacturero alcanza 18,9\%, Fenalco (2017).

En Colombia cerca del 10\% de las importaciones son de contrabando, dentro de las cuales el $10 \%$ es contrabando abierto, mientras que el $90 \%$ es técnico, siendo la industria de los textiles el sector más afectado. Esto no sólo genera una pérdida anual para las empresas de USD6.800 millones, sino que además se dejan de recaudar aproximadamente USD1.8 billones en impuestos que servirían para invertir en pro del desarrollo del país. Es difícil controlar la subfacturación debido a que el proveedor del exterior muchas veces de acuerdo con los acuerdos comerciales que se tienen, no confirma los precios de venta y la autoridad aduanera se queda sin elementos para verificar.

Colombia cuenta con 16 tratados de libre comercio, donde por la acumulación de origen no ha sido posible sacar provecho para el sector textil; el aprovechamiento de los TLC para los sectores productivos radica en el entendimiento de las normas de origen y su presencia en los procesos productivos de la industria textil y confección. Siendo así la gerencia efectiva de las organizaciones productoras y exportadoras quienes a través de la estrategia organizacional apunten hacia los mercados internacionales cumpliendo con la normatividad. 
El gobierno nacional ha apostado por la implementación de proyectos con tres enfoques, con el objetivo de mitigar el resultado negativo del sector textil: 1) Proyecto Fabricas productivas la cual contara con una inversión superior a los \$21.000 Millones de pesos, 2) Plan nacional de desarrollo fortalecerá los controles de contrabando aduanero textil, así como el apoyo a las entidades tributarias.3) Plan de ordenamiento productivo con incremento de siembra de algodón, con metas de duplicar la producción colombiana con el fin de abastecer el $41 \%$ de la demanda interna para el 2020.

\section{Metodología}

Para el desarrollo de esta investigación se emplearon varias metodologías de gestión; buscando desarrollar estrategias competitivas con el fin de implementar políticas y crear una estructura sectorial que sea favorable y conduzca a la asignación de recursos que permita la consecución de los objetivos. (Fernández, 2006, p. 22).

Iniciamos el proceso con La matriz PESTEL, la cual permitió identificar 15 factores críticos de éxito de las diferentes variables del entorno en el que se encuentra inmerso el sector textil colombiano; En esta matriz se analizaron factores externos en el aspecto político, económico, social, tecnológico, ecológico y legal y su impacto. Los resultados de esta matriz nos proveen una visión del macroentorno por lo que los resultados permiten evidenciar oportunidades y amenazas.

El modelo del análisis de las cinco fuerzas es una herramienta de análisis estratégico de Michael Porter que permitió realizar una identificación de 15 factores críticos de éxito del microentorno; enfocado al poder de negociación con los clientes, poder de negociación de 
los proveedores, la rivalidad entre competidores, la amenaza de los entrantes, y los efectos que implicaría en el sector textil la entrada de nuevos sustitutos.

Teniendo en cuenta la postulación de (David, 2011); el cual afirma que la gestión estratégica puede basarse en la identificación de las oportunidades y amenazas dando focalización para construir estrategias competitivas; cada uno de los factores críticos de éxito identificados en el PESTEL y PORTER; se calificó con un impacto entre 0-3; donde 0 es nulo impacto en las estratégias competitivas y 3 es impacto critico en las estrategias competitivas.

Posterior se realizó un ranking de los 15 factores críticos de éxito en cada una de las matrices PESTEL y PORTER; se ordenó por impacto los factores críticos de éxito, donde 1 identifica el de mayor relevancia y 15 el de menor relevancia en el desarrollo de estrategias competitivas del sector Textil.

Posterior se realizó la ponderación del impacto del macroentorno y microentorno identificando el ambiente favorable o desfavorable para el desarrollo de las estrategias competitivas y por último, una visualización grafica de estos componentes.

Resultados de Investigación

- Ponderación Matriz Pestel

Analizando los componentes Políticos; económicos; Sociales; Tecnológicos, Ecológicos y Legales permitiendo tener una visión global del macroentorno del sector textil en Colombia la calificación del impacto y el ranking dado a cada uno de los factores evaluados bajo el concepto de construcción de ventaja competitiva da como resultado una posición ventaja débil en las oportunidades y amenazas encontradas con una calificación de 
-3,4; dado por un ambiente favorable representado por los factores políticos, legales y sociales; evidenciando las políticas gubernamentales de fortalecimiento de los sectores productivos; como Fabricas productivas; Plan nacional de desarrollo con enfoque al control del contrabando y aduanero textil y el plan de ordenamiento productivo con enfoque a duplicar la producción de algodón con el fin de abastecer el 40\% de la demanda interna. Con un enfoque normativo al cumplimiento de estos factores; hoy más que nunca el factor social colombiano es apto para el desarrollo de los sectores industriales de la economía colombiana; la disminución en 10 años del número de secuestros esta hoy en día en el 94\%, y la percepción de la seguridad ha incrementado y fomenta la inversión extranjera directa.

Se evidencia Un ambiente desfavorable en los Factores Tecnológicos con un -19.5\%; ecológico del -10,5 y económico con el -2,0. Se puede evidenciar 2 fenómenos fundamentales que son directamente proporcionales al desarrollo futuro del sector industrial textil y en los cuales Colombia no está a vanguardia. 


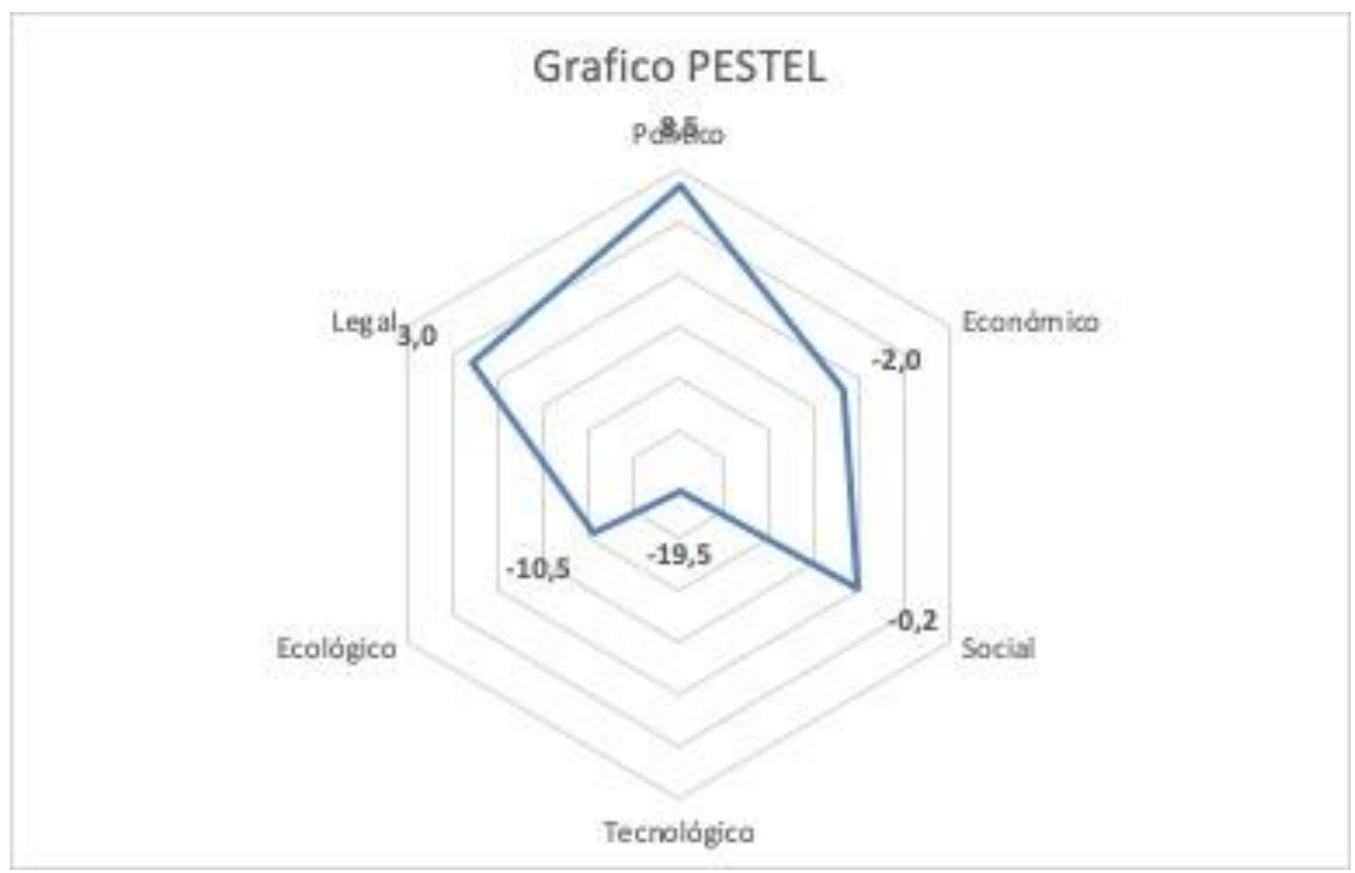

Ilustración 1; Ponderación factores críticos de éxito PESTEL

Fuente: autora (2019)

Las Tendencias Tecnológicas en la cadena productiva del sector textil deben garantizar un desarrollo industrial 4.0; incursionando no solo en maquinaria tecnológica que permita la competitividad sino implementación de la tecnología en el proceso de gestión estratégica; desde la adquisición de materias primas hasta el desarrollo de omnicanalidad para llegar al consumidor final a través de las diferentes plataformas tecnológicas que generan valor e impacto en el sector Textil.

Las características de la implementación de Industria textil 4.0; están marcadas fundamentalmente por procesos tecnológicos que permitan con agilidad, control y automatización de procesos; Según el informe anual de desarrollo industrial de la ONUDI; la innovación de procesos tiene una influencia diferente a la productividad del sector con la mejora de los sistemas y la modernización de las cadenas. El Foro Económico Mundial; 
afirma que hay una correlación directa entre invertir en transformación de las cadenas productivas y el PIB de la economía; con un aumento del 10\% y la digitalización genera un incremento del $0,7 \%$.

Las empresas que no se transformen digitalmente están condenadas a desaparecer. Aunque Colombia ha avanzado en los últimos 7 años en innovación y emprendimiento; se hace necesario un crecimiento a un ritmo acelerado. Después de ocupar en el 2010 el puesto 90 en el Global Innovation Index, indicador que evalúa las economías más innovadoras entre 128 países, en el 2017 quedó en la posición 65, con calificación de 34,78. Y en emprendimiento, en el cual estaba en el puesto 79 en el 2015, en 2016 subió al 44. Según información de la cámara colombiana de comercio electrónico en el 2017.

La ecología como eje central de la industria Textil; Colombia incursiona tímidamente en el desarrollo sostenible del sector textil colombiano; las puestas en marcha de proyectos que incluyan la ecología se limita a empresarios emprendedores d Antioquia y Eje cafetero quienes han desarrollado un programa de aprovechamiento integral de las fibras naturales; Mas sin embargo estos esfuerzos incipientes no permiten una focalización en crear a gran escala estrategias competitivas con este factor crítico de éxito. Los empresarios argumentan que la implementación de proyectos verdes conlleva una inversión tecnológica muy alta y no son reconocidas con beneficios para el sector.

- Ponderación Matriz Porter:

Analizando los componentes Poder de negociación de Clientes; Poder de negociación de proveedores; Poder Rivalidad entre competidores; Amenaza por entrada de nuevos competidores y Amenaza por entrada de sustitutos; permitió tener una visión global del 
microentorno del sector textil en Colombia; la calificación evidencio un ambiente desfavorable en general de 4,3; con un porcentaje de dado a cada uno de los factores evaluados bajo el concepto de construcción de ventaja competitiva.

Se encontró ambiente favorable representado por los factores Rivalidad entre competidores y Amenaza de nuevos productos sustitutos; evidenciando la oportunidad competitiva que tiene el sector al seguir afianzando la historia textil colombiana enmarcada por afrontar retos y oportunidades a lo largo de su proceso de crecimiento y consolidación, esto se ha logrado con la construcción y fortalecimiento de las agremiaciones y la comunicación de la calidad del sector a través de las ferias establecidas en Colombia que hoy son referente de industria textil para Latinoamérica; Colombiamoda; Bogota Fashion Week e Inexmoda; potencializan el sector y sus ventajas estratégicas competitivas.

Se evidencia Un ambiente desfavorable en los Factores Amenaza de nuevos competidores entrantes -16, Poder de negociación con clientes -6 y Poder de negociación con proveedores -4 .

El poder de negociación de proveedores evidencia una dependencia externa de la producción nacional; el $60 \%$ de las materias primas son importadas y esto no solo perjudica el sector por el incremento inmediato del costo de producción y pago de aranceles; sino adicional se está obstruyendo el desarrollo de una puesta en escena global en la cual podríamos ser competitivos como lo es incursionar en la utilización de materias primas ecológicas y producción verde, con aprovechamiento de los recursos naturales que Colombia posee. 


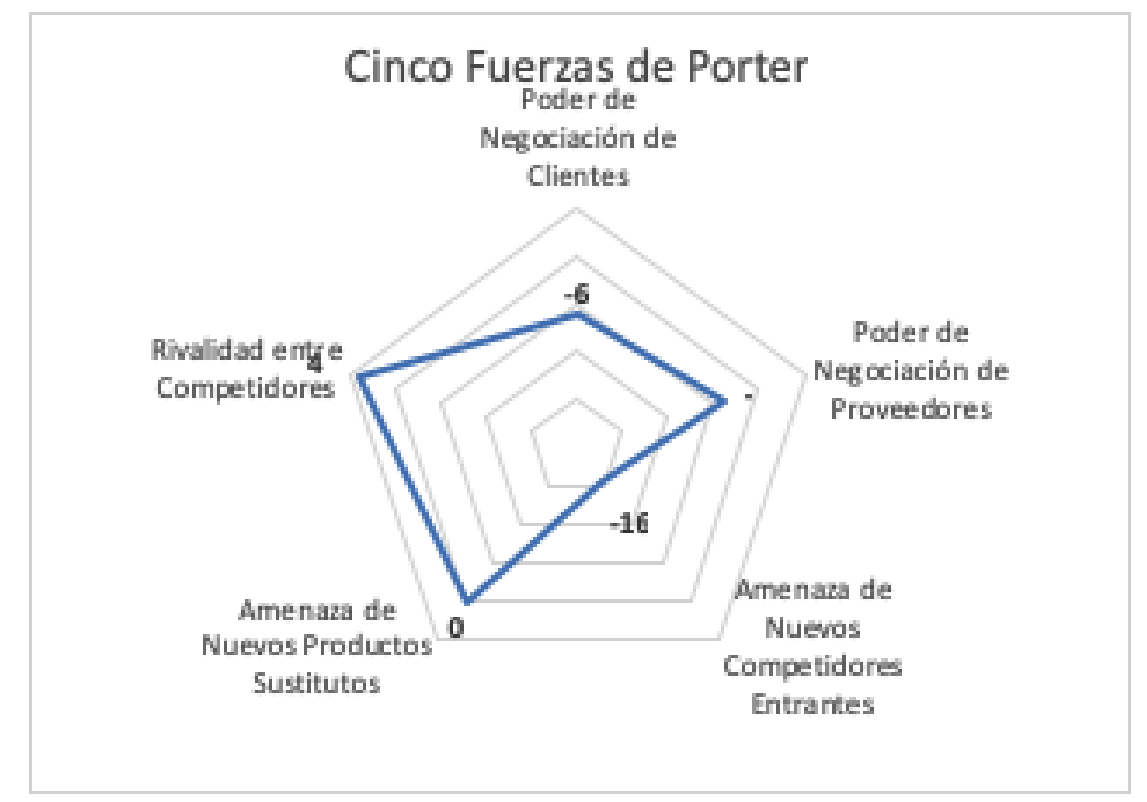

Ilustración 2; Ponderación factores críticos de éxito PORTER

Fuente: autora (2019)

La amenaza de competidores Entrantes; está centralizada en la tendencia de estos a satisfacer los cambios de paradigmas que se vienen desarrollando en el mercado, la manufactura inteligente la migración a materias primas naturales y ecológicas y la implementación del diseño y tecnología, son elementos que redundan de manera trascendental en el desarrollo textil global.

El poder de negociación de clientes, esta evidenciado que han cambiado sus hábitos de compra, hoy Vemos consumidores más informados ligados a la omnicanalidad para realizar compras eficientes; el showrooming y el Webrooming son tendencias que impactan el paradigma de como compran los consumidores y las empresas que quieran tener éxito deberán desarrollar e implementar una fuerte estrategia de transformación digital. Sin desconocer que el sector debe afianzar las posibilidades técnicas como productivas, asentadas en procesos como el respeto y cuidado del medio ambiente, una producción menos 
contaminante y con menor emisión de $\mathrm{CO}$, empaques verdes y mayor reciclaje. (Dekker, Fleischmann, Inderfurth, \& van Wassenhove, 2013).

\section{Reinventando "Competitividad e innovación en el Sector Textil"}

Los sectores industriales pueden desarrollar ventajas competitivas, a través de: 1) La organización de los recursos humanos y materiales (Diaz 2003) 2) Reduciendo costos de producción; contando con productos diferenciados y focalizados (Porter, 1989) y 3) Definiendo estrategias competitivas desarrolladas bajo el análisis de las oportunidades y amenazas existentes en el entorno. (David, 2011).

Para ser competitivos es necesario conocer los factores que influyen en el entorno del sector y el desarrollo del mismo Oportunidades y Amenazas; siendo posible identificar las variables que inciden en la competitividad, los cambios de los mercados, las tendencias y focalizarnos en dichas estrategias; con la investigación relacionada "la sostenibilidad" debe ser el camino de la propuesta estratégica del sector.

Los consumidores hoy en día cuentan con infinidad de opciones a la hora de elegir prendas de vestir; La moda y las tendencias de temporada han cambiado los hábitos de consumo en las familias alrededor del mundo; la llegada del fast Fashion o low Cost Textil ha hecho que en apenas 15 años la producción de ropa en todo el mundo se haya multiplicado por dos, según un estudio de la Fundación Ellen MacArthur. Si en el 2000 se fabricaban 50.000 millones de prendas, en 2015 alcanzaron las 100.000, y todo apunta a que el ritmo ha seguido creciendo.

Para el 2020 las tendencias parecen ir dirigidas hacia un público más reflexivo que busque una integración en la industria textil; donde no solo se reciba prendas con diseños y moda; sino que estas se integren conceptos de mayor funcionalidad con desafíos 
tecnológicos, abriendo camino hacia escenarios donde se incluya la responsabilidad social y ambiental en la oferta.

El informe, elaborado en colaboración con la consultora McKinsey\&Company, y a partir de datos del Banco Mundial, muestra una preocupante tendencia derivada de la sobreoferta de productos textiles: la ropa está masivamente infrautilizada. En esta última década y media, el tiempo de uso que se le da a una prenda antes de desecharla es $36 \%$ inferior. Es decir, hoy se usa una prenda menos de 160 veces de media antes de deshacernos de ella.

Es aquí donde las políticas ecológicas son un incidente trascendental en el sector Textil, según la ONU está es la segunda industria más contaminante después del sector petróleo, produce el $10 \%$ de las emisiones de carbono en el mundo y el $20 \%$ de las aguas residuales; Un estudio de la Universidad de Plymouth (Reino Unido), encontró que la ropa de poliéster y acrílico arroja miles de fibras plásticas tóxicas con el lavado, enviando otra fuente de contaminación plástica por el desagüe y, finalmente, hacia el océano. Aunque se han implementado políticas globales y sectoriales para mitigar los daños, el avance es muy lento y se continúan generando serios impactos a los ríos y los océanos.

La ecología cohesiona el diseño y la responsabilidad social; proponiendo el auge de pequeñas tiradas y ropa especializada: caracterizando producción local y bajo demanda y esta no requiere grandes inversiones previas y se beneficia de conocer al cliente; permitiendo de innovar y agregar valor en diseño, tecnología y ecología. Se estima que en la próxima década el incremento del uso de las bases naturales, sumado a la aceleración del mercado y la demanda en estampados e imágenes impulsarán el crecimiento de la técnica digital entre un $15 \%$ y un $22 \%$ acumulado en el país y la región. FashionWeek (2019). 
Colombia incursiona tímidamente en la construcción del sector textil, sostenible, el comité ambiental de la Organización de las Naciones Unidas (ONU) define la sostenibilidad como "el desarrollo que cubre las necesidades de las generaciones presentes, sin poner en riesgo la capacidad de las futuras generaciones de cubrir esas mismas necesidades"; esto implica la articulación de lo social, económico y ambiental. Un grupo de empresarios emprendedores del Antioquia y Eje cafetero han desarrollado un programa de aprovechamiento integral de las fibras naturales principalmente las extraídas del fique, yute, corteza de coco, lino y algodón.; junto con los laboratorios de diseño e innovación textil. Fenalco (2017).

Según la propuesta terminológica de Luque (2018) Se establece los siguientes conceptos que favorecen la implementación de sostenibilidad clasificados en dos dimensiones los cambios de hábitos que han desarrollado la ciudadanía a la hora de comprar y la presión ejercida por los mismos mediante el empuje social. Una segunda dimensión establece los beneficios para los sectores de implementación de una cadena verde, con reducción de costos y un componente alto de innovación en los nuevos procesos circunstancia que se traduce en una ventaja competitiva sin precedentes y un futuro nicho de mercado.

Desde la dimensión del consumo podemos evidenciar que emerge un nuevo consumidor, responsable que ejerce una presión abrumadora por la protección del medio ambiente, Chien \& Shih (2007), aquel que es consciente de sus hábitos de compra, donde con principios y una escala de valores diferencial, considera elementos como procedencia del producto, producción manufactura, derechos humanos, uso experimental con animales. Chizaryfard, Samie y Pal, (2018). Involucrando aspectos medioambientales y éticos 
derivados de la responsabilidad social empresarial y su relación con el contexto social y cultural. Mohr, Webb, \& Harris (2001).

Desde la dimensión de la construcción de cadenas de suministro verde para el sector textil podemos encontrar la construcción de ventajas competitivas Sarkis, Zhu, \& Lai, (2011) evidenciada en eficiencias productivas, reducción de desperdicios, mejora del desempeño ambiental ahorra costos alcanzando los objetivos y la cimienta un buen nombre en el mercado.

Los Elementos que inciden y promocionan la sostenibilidad para el desarrollo de ventajas competitivas del Sector Textil deben abordarse como país desde:

Ámbito Social, incluyendo legislación sólida, Órganos de negociación colectiva con facultades de vigilancia, verificación, control y sanción.

El Desarrollo Sostenible: Con productos elaborados de manera limpia, Deuda ecológica, Reciclaje de prendas, nuevos hábitos de consumo responsable.

Ámbito Económico: Nuevos modelos económicos de las cadenas, economía verde, azul economía colaborativa social y solidaria. Control de Dumping económico además de la obsolescencia programad y la adherencia a acuerdos globales.

Ámbito tecnológico: utilización e investigación de sustancias menos contaminantes, Establecimiento del principio de precaución, nuevos procesos logísticos sincronizados con los clientes.

Como sector país la transformación y el reinventarse puede estar asociado al aprovechamiento estratégico del análisis de las amenazas. Construyendo un sector textil 
verde que sea referencia en Latinoamérica, con cambios significativos desde la raíz; el aprovechamiento de la crisis puede impactar en resultados a largo plazo y que agreguen valor.

Conclusiones

En esta investigación se observa que desde finales del siglo XVIII; donde se inicia el desarrollo de una producción textil artesanal, este tipo de manufactura ha tenido un papel de impacto en la economía colombiana, y pese a todo el recorrido de la historia los factores críticos que afronta se mantienen en el tiempo y no han sido afrontados de manera novedosa.

El sector textil y desarrollo del mismo, ha estado marcado por una tendencia de políticas económicas proteccionistas; la competitividad solo es posible generarla cuando se compara con las mejores condiciones del mercado internacional; hoy en día el único subsector que puede ser competitivo en el mercado internacional es la confección; aunque tiene debilidades en el acceso a las materias primas; el diseño y la calidad caracterizan este.

La economía colombiana hoy en día presenta dificultades en los escenarios que presenta para el desarrollo competitivo del sector textil, políticas económicas totalmente abiertas a los mercados internacionales, pero sin políticas internas que fortalezcan de manera contundente la competitividad del sector; Una moneda devaluada y con consecuencias inmediatas en el acceso de insumos y materias primas; confluyen con la desaceleración económica que se afronta para ahondar la situación del sector.

La maquinaria y la tecnología del sector se estiman obsoletos frente a los procesos de innovación de la industria internacional textil; el crecimiento de innovación en la manufactura colombiana crece solo al $7 \%$. 
Para ser competitivos es necesario conocer los factores que influyen en el entorno del sector y el desarrollo del mismo Oportunidades y Amenazas; siendo posible identificar las variables que inciden en la competitividad, los cambios de los mercados, las tendencias y focalizarnos en dichas estrategias; con la investigación relacionada "la sostenibilidad" debe ser el camino de la propuesta estratégica del sector.

Los consumidores, son cada vez más conscientes de la limitación existente en los recursos naturales, del nivel de gasto y sus implicaciones, así como de sus condiciones personales y culturales. La acción de compra ha cambiado y la responsabilidad ecología juega un papel vital en el desarrollo de tendencias y la apertura del nicho de mercado.

El sector empresarial en conjunto con adecuadas políticas gubernamentales debe enfocar sus esfuerzos es la construcción de RSE, mediante el fortalecimiento de autoridades públicas de carácter global, en aras de un crecimiento más sostenible y con menos subterfugios, en muchos casos explorados, por parte del sector textil.

El desarrollo del sector textil hoy colombiano tiene la capacidad para reinventarse y crear un compromiso con el entorno y sostenibilidad. Un modelo de negocio, que no esté únicamente asentado en el beneficio a corto plazo o que comprometa generaciones futuras, sino que mire más allá, en el balance natural del sistema. 


\section{Referencias}

Acosta, A; (06 de Agosto del 2017);) Hilando delgado: Así le va a la industria textil colombiana; Revista Dinero; Recuperado https://www.dinero.com

Articulo Fibras vegetales colombianas como refuerzo en compuestos de matriz polimérica; Textiles con fibras Naturales; Artesanías de Colombia, Recuperado http://artesaniasdecolombia.com.co

Bayons Beatriz, raymond Pierre, Vida y muerte del algodón y los tejidos santandereanos: historia económica y tecnológica de la desaparición del cultivo y de la industria casera del algodón, Bogotá: Ecoe ediciones, 1987.

BOTERO, Fernando. Arranca la Gran Industria. Universidad Nacional de Medellín. Documento en línea. Disponible en www.colombialink.com. [Visitado el 2 de Julio de 2019]

Cabrea M (22 de Agosto del 2017) La crisis del sector textil; Revista Portafolio; Recuperado https://www.portafolio.co

Camacho Roldán, Salvador, Mis Memorias, Medellín: ed. Bedout, 1900. http://www.lablaa.org/blaavirtual/historia/memor/memor14.htm,

Camacho roldán, Salvador, Escritos varios, Bogotá: librería Colombiana, 1892-1895. Citado por: ocampo José antonio, “Comerciantes, artesanos y política económica en Colombia, 1830-1880”, en Boletín Cultural y Bibliográfico, núm. 22, v. XX vii . Bogotá: Banco de la república, 1990.

Castrillon J;(Julio 4 del 2018) Colombia puede ser una potencia del comercio electrónico Revista Portafolio; Recuperado https://www.portafolio.co 
Castilla J; (3 de Mayo del 2019); Mincomercio advierte sobre la inconstitucionalidad de los aranceles a la industria textil; Diario La República; Recuperado $\underline{\text { https://www.larepublica.co }}$

Castro Castell, Ofelia, Ojeda Pérez, Robert, Sánchez Murillo, Luisa Fernanda, Reyes Ospina, Nicole Alejandra, Rodríguez Núñez, Karen Vanesa, Análisis de las políticas de comercio exterior en Colombia para disminuir el ingreso de mercancías del sector textil y calzado provenientes de China. Revista VIA IURIS 2016 Recuperado en: http://www.redalyc.org/articulo.oa?id=273950435008> ISSN 1909-5759

Codina Jiménez, A. (2011). DEFICIENCIAS EN EL USO DEL FODA CAUSAS Y SUGERENCIAS. Revista Ciencias Estratégicas, 19 (25), 89-100.

Cerrillo A; (31 de Octubre de 2017); El 'low cost' multiplica los residuos textiles Diario La Vanguardia; Recuperado https://www.lavanguardia.com

Contrabando,(2016) la Camisa de Fuerza del Sector Textil y Confecciones - Revista Sectorial. Legiscomex. (2012). Textiles y confecciones en Colombia. Disponible en: https://www.legiscomex.com

COTTE POVEDA, Alexander. Violencia, política económica y crecimiento económico en Colombia. Universidad del Valle. 2003. Disponible en http://indh.pnud.org.co/files/rec/AlexanderCote.pdf. [Visitado el 2 de Julio de 2019]

DE JUAN, M. (2006): Sector textil-confección): Preferencias de los consumidores por formato y surtido Obtenido de: http://www.mercasa.es

Isla P (18 de Marzo del 2016) Nueve cosas que han hecho de Inditex la mayor empresa textil del mundo. Obtenido de: http://economia.elpais.com. 
DIAZ, C. (2014): El secreto de Inditex: 48 horas para abastecer a todas las tiendas del mundo. Obtenido de: http://www.economiadigital.es/ Díaz, I. (2003). Marketing y competitividad: ¿Relación o contradicción? Economía y Desarrollo, 132(1), 112-119.

David, F. R. (2011). Strategic management: Concepts and cases (13th ed.). Upper Saddle River: Prentice Hall.

Diario el Espectador (10 de Septiembre del 2017); En 2022 habría 389 millones de conexiones 5G en el mundo; Diario el Espectador; Recuperado https://www.elespectador.com

Diario La República; (28 Agosto de 2017) Cinco razones por las que el sector textil y de confecciones debe reinventarse; Recuperado https://www.larepublica.co

Informe Especial Textil y confección Inexmoda (Mayo 2019) Recuperado http://www.saladeprensainexmoda.com

Informe desempeño del sector textil y confección (2017) Recuperado https://www.supersociedades.gov.co/delegatura_aec/estudios_financieros

Informe Camara de Comercio de Bogota (2018); Industria Textil Colombiana 2018: telas inteligentes y tendencias ecológicas; Recuperado https://www.ccb.org.co

GARAY S. Luis Jorge. Colombia: estructura industrial e internacionalización 1967 1996. Biblioteca Virtual Luis Ángel Arango. Disponible en http://www.lablaa.org/blaavirtual/economia/industrilatina/205.htm. [Visitado 2 de Julio de 2019].

Gómez Cely, Ángela, Molano, Uliana y Jaime Silva, Sandra, “Textiles en Colombia al finalizar el siglo XIX: producción artesanal, importación e industrialización”, Cuadernos de 
Curaduría, museo nacional de Colombia, núm. 11, julio - diciembre, en: http://www.museonacional.gov.co/inbox/files//docs/Textiles_en_colombia.pdf

Gonzalez T, (21 Enero de 2019); El Gobierno colombiano apuesta por la industria textil con nuevas 'zonas Especiales' y beneficios; Revista Fashion Network. Recuperado https://pe.fashionnetwork.com

Jimenez F; (23 de Enero del 2019) Tratados comerciales, un telar que requiere ajustes; Diario el Colombiano; Recuperado https://www.elcolombiano.com

Linares; Edgar (2008), Fibras vegetales utilizadas en artesanías en Colombia, Artesanías de Colombia S.A. Ministerio de Comercio, Industria y Turismo Recuperado https://www.researchgate.net.

Lozano M, (13 de Marzo del 2019) El entendimiento de la normatividad de origen en la industria textil - confección; Revista Acuerdos derecho económico internacional, recuperado http://acuerdosrevista.mincit.gov.co

Martínez Carreño, Aída, "la industria femenina de los sombreros 24\% de las exportaciones en 1858”, en revista Credencial Historia, Bogotá: julio de 1993, edición 43.

MAYOR MORA, Alberto. Historia de la Industria Colombiana 1886 - 1930. Nueva Historia de Colombia. Ed. Planeta Colombiana Editorial S.A. 1989.

Meleán Romero, Rosana, Reinventar el negocio: Para vender más barato (o más caro) Autor: Josep-Francesc Valls Giménez. Negotium [en linea] 2017, 13 (Noviembre-Sin mes) : [Fecha de consulta: 8 de julio de 2019] Disponible en:<http://www.redalyc.org/articulo.oa?id=78253678007> ISSN 
Moncayo C; (29 de Junio del 2017); Medidas para que el sector textil y confecciones siga creciendo; Instituto nacional de Contadores Públicos; Recuperado $\underline{\text { https://www.incp.org.co }}$

Moreno M; (21 de Marzo del 2018) Las ciudades del país con más y menos problemas de economía - Diario el Tiempo; Recuperado https://www.eltiempo.com

Monterrosa H, (21 de mayo de 2019) El peso colombiano se ha devaluado 10,3\% frente al dólar en un año; Diario la Republica; Recuperado https://www.larepublica.co

Murillo O; (20 de Enero del 2019) Aumentaron un 47 \% las denuncias por extorsión Diario el Tiempo; Recuperado https://www.eltiempo.com

Pelayo Díaz, Y., \& Vargas Sánchez, A., \& Lévy Mangin, J. (2003). Análisis estratégico del sector envasador de aceite de oliva en España. Recomendaciones para el subsector cooperativo. CIENCIA ergo-sum, Revista Científica Multidisciplinaria de Prospectiva, $10(2)$.

Prieto Piña, D. (2015). Análisis de los factores del entorno bajo el enfoque de PESTEL y DAFO para el proyecto empresarial "FEQUIMA": Portal web de maquinarias, equipos y herramientas en Brasil. Sapienza Organizacional, 2 (3), 129-152.

Porter, M. (1982). Estrategia competitiva. México: CECSA.

Porter, M. (1989). Ventaja competitiva. México: CECSA.

Porter, M. (1990). ¿Dónde radica la ventaja competitiva de las naciones? HarvardDeusto Business Review, 44(1), 3-26.

Porter, M. (1991). La ventaja competitiva de las naciones. Barcelona: Plaza \& Janes Editores. 
Revista Dinero; (18 de Enero del 2019) ¿Qué esperar de 2019 en textiles, moda y confecciones? Revista Dinero Recuperado https://www.dinero.com

Revista Dinero; (29 de Marzo del 2019) Colombia ya ronda los 3 millones de desempleados - Revista Dinero; Recuperado https://www.dinero.com

Revista Dinero; (04/08/2017) Comercio electrónico nacional avanza en madurez, pero aún no es suficiente Recuperado de https://www.dinero.com

Reyes G; (27 de Mayo del 2019); Aumento del PIB no se traduce en oportunidades para la población - Revista Portafolio https://www.portafolio.co

Sectorial. (2016). El Sector Textil: Entre Innovacióny Contrabando. Recuperado de https://www.sectorial.co

Velasquez M; (9 de Enero del 2019); ¿Cómo pasó Colombia de reportar más de 3.000 secuestros al año a menos de 200 en 20 años? - Revista CNN Español Recuperado $\underline{\text { https://cnnespanol.cnn.com }}$

Vega Cantor, Renán, "liberalismo económico y artesanado en la Colombia decimonónica”, en Boletín Cultural y Bibliográfico, núm. 22, vol. XX vii, Bogotá: Banco de la república, 1990. p. $47-65$.

Vera B; (8 de Agosto del 2018); ¿Por qué la industria textil es la más contaminante después del sector petrolero?; Diario el Espectador; Recuperado https://www.elespectador.com 